\title{
JMLE
}

The National Association for Media Literacy Education's

Journal of Media Literacy Education 11 (1), 32 - 51

https://doi.org/10.23860/JMLE-2019-11-1-2

\section{Exploring Critical Awareness of Media and Teacher Education: An Experience with Colombian ELT Pre-Service Teachers}

\author{
Camillo Dominguez \\ University of Antioquia, Colombia
}

\begin{abstract}
Today's media spectacle is shaping societies, cultures, and even our own values and identities at a global scale. Even though media can be used to promote education, democratic self-expression, and social progress, it is often used to perpetuate social injustices, prejudice, and violence. Media texts are exponentially displayed in physical and virtual public spaces and their impact on humanity is unimaginable. Teachers of all fields face the challenge and the responsibility to educate sensitive humans who are able to critically consume or produce media messages. English language teachers are no exception. In this paper, the author describes a qualitative research study conducted by a teacher educator exploring how a group of Colombian pre-service English teachers developed critical awareness of media as they critically deconstructed advertisements displayed in the public spaces of their rather rural communities. Implications for teacher education emerging from this study and new questions for further research will be presented.
\end{abstract}

Keywords: critical awareness, media literacy, teacher education, ELT

In our world today, humanity is exposed to media in multiple unmeasurable and even dangerous ways. Media texts are exponentially displayed in physical and on-line public spaces. Regardless the age, everyone can access media texts in a myriad of formats (e.g., advertisements, TV commercials and shows, popular music video-clips, online videogames, films) (Gainer, 2010). These texts are powerful enough to shape our societies and cultures (Kellner \& Share, 2007), the way we interact with the world (Morrell, 2014), and even individuals' own values and identities (Begoray, Wharf Higgins, Harrison, \& Collins-Emery, 2013). Media texts are commonly used to misinform, to sell "problematic" ideologies (Kellner \& Share, 2005, pp. 371-372, Kellner \& Share, 2007, 64), and to perpetuate social injustices, prejudice, and violence in the forms of sexism, racism, ethnocentrism, homophobia, for example (Morrell \& Duncan-Andrade, 2002). 
Given that many people are not aware of the commonly invisible ways that media influence, educate, and construct individuals (Kellner \& Share, 2005), educators play an important role to prepare learners of all ages to critically navigate today's problematic and even harmful media landscapes. Teachers of English learners are no exception. Besides facilitating student learning or acquisition of a foreign, second, or additional language, English teachers face the challenge of nurturing critical awareness of media through their instruction. But, are English teachers prepared for such task in Colombia?

Fortunately, there is a growing number of efforts serving this purpose in our Colombian ELT community made by in-service and pre-service English teachers. Among the in-service teachers doing critical work with media texts are Vargas (2010), Mora and Muñoz (2012), Perez (2013), Arias (2017), and Camargo (2017). Vargas (2010), a university English teacher, has acknowledged that critical analysis of media sociocultural representations may lead to the education of citizens able to interact with today's mediated world. Mora and Muñoz (2012), two teacher educators, critically deconstructed commercials of on-line English courses and advocate for fairer representations of non-native English teachers. Perez (2013) encouraged a group of $10^{\text {th }}$ graders to reflect about social issues in her determination to educate more sensitive citizens at a public school. Arias (2017) critically deconstructed food advertisements with a group of kids in an English program for children. Finally, Camargo (2017) critically evaluated media texts with a group of 11 th graders at a private school.

Pre-service English teachers have begun to explore how to critically use media in K-11 contexts in the last stage of their undergraduate during their studentteaching. Among such pre-service educators are Guapacha (2015), Guerra (2015), Alzate (2016), Aristizábal (2016), and Orrego (2016). Guapacha (2015) engaged a group of $11^{\text {th }}$ graders, at a female school, in the critical deconstruction of media representations of women. Guerra (2015) analyzed bodily representations in advertisements with a group of $10^{\text {th }}$ graders. Alzate (2016) promoted critical reflections about Reggaeton video-clips among $10^{\text {th }}$ graders. Aristizábal (2016) focused her work in the critical analysis of fashion advertisements with $10^{\text {th }}$ graders. Orrego (2016) critically deconstructed news articles with a group of $5^{\text {th }}$ graders.

Seeking to expand the work done in Colombian English teacher education programs, I embraced the challenge of developing critical awareness of media in an English writing composition course pertaining to the third semester of a fiveyear foreign language teacher education program. This paper describes a qualitative research study that I conducted in 2015 in which I examined how a group of preservice English teachers developed critical awareness of media as they critically analyzed advertisements displayed in the public spaces of their rather rural communities. The following sections will present the theoretical framework that informed this study and will describe this study's setting, participants, research methodology, process of data collection and analysis, findings, discussion and conclusions. Implications for English teacher preparation programs and some new questions for further research will also be presented. 


\section{THEORETICAL FRAMEWORK}

\section{Developing Critical Awareness of Media in the Language Classroom}

The notion of critical awareness in the language education field was first introduced by Freire (1974) as concientizaçao. According to him, being critically aware, as opposed to being naïve, means to engage in in-depth analysis of problems, to practice dialogue and reflection, and to reject passive positions. People who become critically aware of their context, their reality, and of their human condition are people who exercise the right of democracy by making their own choices, because "to every understanding, sooner or later an action corresponds" (p. 39). Accordingly, being critical aware of media would involve problematizing media and engaging in in-depth analysis of media texts. It would also involve active reflection, and rejection of passive positions by making informed choices.

\section{Critical Analysis of Media Texts}

Critical literacy and critical media literacy scholars have proposed various frameworks to critically analyze texts. For this study, drawing on different authors, I divided the critical analysis of media texts in two parts: unveiling hidden messages in media and deconstructing the non-neutral nature of media texts.

Unveiling media hidden messages. Media texts are social constructions that adopt and reproduce messages about history, culture, and ideology (Kellner \& Share, 2007; Luke, 2012; McLaughlin \& DeVoogd, 2004; Morrell, 2002). As such, they include and omit "particular values, versions of human identity, human action, histories, races, cultures, and social classes" (Luke, 2000, 456) which may perpetuate socio-cultural issues related to "ideological notions of white supremacy, capitalist patriarchy, classism, homophobia, and other oppressive myths" (Kellner $\&$ Share, 2007, 62). At the same time, these texts may position readers in relation to fragmented worldviews (Luke, 2000; Kellner \& Share, 2005). By being aware of the hidden messages conveyed by media, readers could become more sensitive to the "social and political injustices" perpetuated by media texts, which are based on gender, race, and class inequalities or discrimination (Gainer, 2010, 365; Kellner \& Share, 2005, 370). Besides, they could problematize such messages and emancipate themselves from media ideological and power forces. They could also decide to engage in actions aiming at transforming and re-constructing their sociocultural and political realities (Luke \& Woods, 2009; Morrell, 2002).

Deconstructing the non-neutral nature of media text. Media texts are never neutral. They have the power to construct, shape, and reshape worlds "in particular normative directions with identifiable ideological interests and consequences for individuals and communities" (Luke \& Woods, 2009, 9). Besides, they can indoctrinate readers by shaping their beliefs, values, identities, and even behaviors (Begoray et al., 2013; Gainer, 2010; Morrel, 2014). Therefore, to analyze the nonneutrality of these texts, scholars converge in the relevance of critically examining aspects of media texts such as their purposes, audiences, and the representations of people and communities that they portray.

First, media texts are used for various motifs such as everyday selfexpression, identity formation, economic exchange, cultural engagement, religious 
experience, civic life, commerce, industry, and leisure (Luke \& Woods, 2009). The analysis of the purposes of media texts facilitate the understanding of how texts producers always "make various decisions as to how to influence people's interpretations and reactions towards the messages they send" (Jolls, 2012, 29).

Second, media texts target specific audiences and exclude others. The analysis of how this occurs would allow readers to understand how human relations are determined by media, to challenge them, and to take an active role when negotiating meaning and resisting media discourses (Kellner \& Share, 2005).

Third, media representations have the power to influence people's conception of themselves and of the world (Kellner \& Share, 2005; Morrel, 2014) as they tend to be naturalized (Kellner \& Share, 2005). Then, by representing some groups of people and by excluding others, these texts not only represent positively and benefit dominant groups, but also "disadvantage marginalized and subordinate ones" (Kellner \& Share, 2005, 370). Therefore, critical examination of who is being portrayed in media texts and who is not, how certain groups of people are being represented or misrepresented, and who benefits from such representations, could help readers gain understanding of how media producers make decisions about "what to include or exclude and how to represent reality" (Kellner \& Share, 2005, 374). Besides, they could also "become investigators of their representations and creators of their own meanings" and empower themselves to raise their voices and become democratic agents of transformation (Kellner \& Share, 2005, 372).

\section{Making Informed Choices: From Awareness to Reflection and Action}

People who become critically aware of their context, their reality, and of their human condition are people who become politicized by making their own choices (Freire, 1974). Actions, however, do not necessarily translate into a collective and activist effort; they may also happen at a personal level, by making personal and conscious decisions for action (Jolls, 2012). Therefore, as students understand how media texts have the power to construct "their worlds, their cultures, and their identities," they could feel empowered to take actions that "reposition themselves in relation to economies, cultures, and dominant ideologies" (Luke, 2000, 453) and to reconstruct their own individual or socio-cultural worlds (Luke, 2000).

\section{RESEARCH METHODOLOGY}

This study can be classified as qualitative research. Qualitative research studies are conducted in natural settings and aim at understanding meanings "from the perspective of those involved." Such studies "focus on a small number of (possibly just one) individuals, groups or settings" and use varied sources of data collection to conduct the analysis (Richards, 2003, 10). Accordingly, with this study, I sought to thoroughly analyze and understand how a small group of preservice English as a Foreign Language (EFL) teachers developed critical awareness of media as they critically analyzed media texts displayed in the public spaces of their communities, engaged in active reflection, and made informed choices, within one particular and natural classroom setting (the Level 3 English composition course). 


\section{Setting and Participants}

This study was conducted in one 64-hour English composition course pertaining to the second year of a foreign language teacher education program offered by a public university in Colombia, at one of its regional campuses. This was the third in a series of four composition courses. It lasted 16 weeks at a rate of one 4-hour session per week. Its main objectives, as stated in the syllabus, were (a) to guide pre-service teachers in reading and writing different kinds of texts, (b) to have them reflect critically about different representations of cultures and foreign languages, and (c) to summarize author's points of view.

The participants in this study, whose ages ranged from 18 to 31, were five female and three male pre-service English teachers: Abril, Carlos, Jessica, Kelly, Laura, Manuel, Sebastián and Vanessa. These names are pseudonyms used to protect participants' identity. By the time they took this class, they had at least passed the previous two English composition courses in the program. They all were born and lived in four different towns located around the University's regional branch and belonged to a middle-low socioeconomic level. These towns were between 40 to 60 kilometers away from the capital city. Their extension ranged from 200 to 450 square kilometers and their population from 45,000 to 100,000 inhabitants approximately. Three of these are municipalities whose economy is based on agriculture, livestock, and handicrafts such as ceramics and guitars. The other one has a very prosperous economy based on trading and on the production of food, fabric, flowers, paper, chemical products, and livestock. These economical activities have turned this town into one of the richest municipalities in Colombia, which could be the reason why there is an increasing gentrification phenomenon, as many wealthy and business people are migrating from the capital city to this municipality.

\section{Course Activities and Tasks}

To develop critical awareness of media in this English composition course, participants completed varied writing tasks about their analyses and reflections throughout the whole in the process. All class activities and tasks were organized in the stages of the framework proposed by Thoman and Jolls (2003) and Jolls (2008): awareness, analysis, reflection, and action. However, I merged the last two stages into one single stage that I called Reflection for Action.

In the awareness stage, teachers lead students to observe and make connections between the texts they interact with in their lives and broader social issues. This stage aims at initiating students in "critical inquiry and exploration" (Jolls, 2008, 66). As such, in this stage, participants completed a series of tasks that helped them observe and make connections between the media texts displayed in the public spaces of their communities and the issues related to them.

First, participants conducted an In-Vivo Encounter in which they explored the public space of their communities, took pictures of as many and as varied texts as they could see, classified the pictures into categories, and then presented their findings to the class. In the context of this course, texts were understood as multimodal (e.g. texts combining images, drawings, and script). 
Second, participants watched, reflected, and held conversations about three videos aiming at raising awareness about the relationship between media, public space, and social issues. The first video was a TED Talk by a French artist named JR: My Wish: Use Art to Turn the World Inside Out. In his speech, JR connects art, public space, community issues, and social transformation. The second video was also a TED talk by Chimamanda Ngozi Adichie, an African story teller. In her talk, The Danger of a Single Story, she provoked reflection about social issues and stereotypes. The third video was a short documentary by Alma Mater UdeA about Victor Muñoz, a visual artist from Medellín. In the documentary Victor speaks about how he critically appropriates the public space of the city of Medellín through his artistic work.

Third, participants negotiated and made decisions about the focus of analysis of their class final projects. To begin with, they all decided to analyze advertisements displayed in the public spaces of their towns. Then, in pairs, they narrowed down their focus of analysis by choosing the advertisements displayed by a specific industry (e.g. real estate, food, and fashion) or by government representatives. Next, participants went on a second In-Vivo Encounter and took additional pictures for their projects with their focus of analysis in mind.

Last, participants wrote an argumentative paragraph explaining the importance/relevance of their class project. In this paragraph, participants briefly gave some information about the industry they chose and the context where the advertisements were located. They also provided the reasons of why analyzing those advertisements critically was important or relevant for themselves and for their communities.

In the analysis stage, teachers would help students expand their understanding of meanings in texts by, for example, using critical questions for their analyses. This stage seeks to facilitate students' deconstruction of texts in order to identify how authors create them and how their choices influence people (Jolls, 2008, 66). In this stage, participants completed a series of tasks that allowed them to unveil hidden media messages about socio-cultural issues and to deconstruct their non-neutral nature of media texts by uncovering purposes, representations and audiences.

First, participants identified social issues related to the advertisements they collected for their projects. They organized their corpus of pictures collected during the awareness stage, categorized them based on the issues that they associated with them (e.g. gentrification, sexism, racism), and selected three advertisements to conduct the critical analysis.

Second, participants received some questions to guide their critical analyses. The questions sought to help them to unveil hidden media messages about sociocultural, political, economic or historical issues and to deconstruct the non-neutral nature of media texts. See questions in Figure 1 below. 
- What messages about socio-cultural, political, historical, or economic issues are portrayed by this text?

- What type of media is being used (e.g. billboard, flyer, window display)? What possible reasons do you think the author(s) had to choose this media?

- What is the purpose of this text?

- Who does the text target? Who is not targeted? Why?

- Which groups of people are being represented in this text? Which are not? What could be some possible reasons or consequences of such representations?

Figure 1

Questions Used for Critical Analysis of Texts

To prepare participants for the analysis, I first modeled the analysis of one advertisement of a jeans brand. In the modeling, I used the same questions and allowed students to contribute to the analysis by sharing their thoughts and ideas. Then, participants conducted a practice analysis. In this practice exercise, they analyzed one of the three advertisements they chose for their critical analysis and received peer and teacher feedback. Next, participants analyzed the other two pictures, received teacher feedback, and made any adjustments as needed.

Third, after the practice exercise, participants studied about advertising by examining some materials from an online course called Advertising and Society, offered by University of Duke in North Carolina (US) through Coursera.org. The course presented a critical perspective about how advertisements work and influence culture and people. With this material, participants learned about the history of advertising, about how advertisements are constructed, and about the messages that advertisements can convey that go beyond what the eyes can perceive. Last, participants presented their analyses, reflections and conclusions in a formal oral presentation.

In the final stage, Reflection for Action, teachers facilitate conversations in which class members contemplate their "philosophical or religious traditions, ethical values, social justice or democratic principles" for "individual and collective decision-making" about how to act (Jolls, 2008, 66). In this stage, students reflected about questions such as "So what?" or "What should we do or think?" after the analysis stage. Consequently, participants analyzed and reflected about transformative actions taken by other people in local and foreign contexts. Then, they evaluated the importance of making informed choices for action and their right to take transformative actions. Participants' actions, if any, were a result of their exercise of the right of democracy to make informed choices.

\section{Data Collection and Analysis}

The data collected encompassed three sets of participants' writing samples, five written reflection tasks, and four questionnaires. Writing samples provided evidence of participants' development of critical awareness of media in each of the three stages of the course. Reflection tasks included open-ended questions that 
revealed participants' reflections and realizations in the different stages of the course. Questionnaires included open-ended questions that showed participants' assessment of how the activities and tasks conducted in each of the three stages of the course helped them develop critical awareness of media. The last questionnaire, which was completed three months after the course had finished, revealed information about participants' action choices. In the reflection tasks and questionnaires, participants could write in Spanish, if needed, to avoid any language barriers when expressing their ideas.

All collected data were individually analyzed several times with a deductive approach. Therefore, I used pre-established categories to guide the examination of participants' gains in (a) unveiling media hidden messages (b) deconstructing the non-neutral nature of Media texts, and (c) making action choices. Trustworthiness was achieved through methodological triangulation, which involves the comparison of data emerging from different data collection techniques (Guion, Diehl, \& McDonald, 2011). First, I analyzed all data individually to facilitate a detailed comparative analysis. Then, I displayed data in matrices, as suggested by Huberman and Miles (1994), and Miles, Huberman, and Saldana (2014). Finally, I conducted a detailed comparative analysis and drew findings.

\section{FINDINGS}

Overall, all eight participants developed their critical awareness of media as they participated in this study. First, they gained awareness about the hidden messages in the advertisements displayed in public spaces. Second, they gained more understanding of the non-neutral nature of media. Finally, all participants made informed action choices after their participation in this study. The following paragraphs provide evidence by presenting single examples of participants' development in each of the aforementioned findings.

\section{Awareness of Hidden Media Messages about Community Issues}

By the end of the study, all participants had expanded their awareness of the hidden media messages about community issues. In the following paragraphs I will present the case of Jessica and Laura as the representation of all participants' progress in this aspect.

At first, unveiling hidden messages was challenging for Jessica and Laura, as evidenced in the diagnosis completed in the first week. In this diagnosis, all participants analyzed a language center advertisement located in a local shopping mall. This advertisement was brought to our attention by one of the participants during the first In-Vivo Encounter. Later, it was democratically selected by the class for the diagnosis task. The advertisement showed an image of Times Square in New York in which many lights and billboards were displayed all around. Among these billboards is the logo of the language center and a sentence that could be taken as a campaign slogan: Experience the world through English. Figure 2 shows this ad.

This advertisement offers ample possibilities for rich critical analysis about problematics related to language, culture and power. For instance, by showing the iconic US city of New York and inviting people to travel abroad, this text could be 
sending messages about the value of US places or culture over the local ones. By inviting people to experience the world through English, this advertisement may be sending messages about linguistic colonialism, as it suggests that the value of English is greater than other languages when traveling, at least. Besides, by repeating the word English and Learning English and by excluding other languages, this text emphasizes on the importance of English language over other languages and suggests that experiencing the world is possible if you speak English, not other languages.

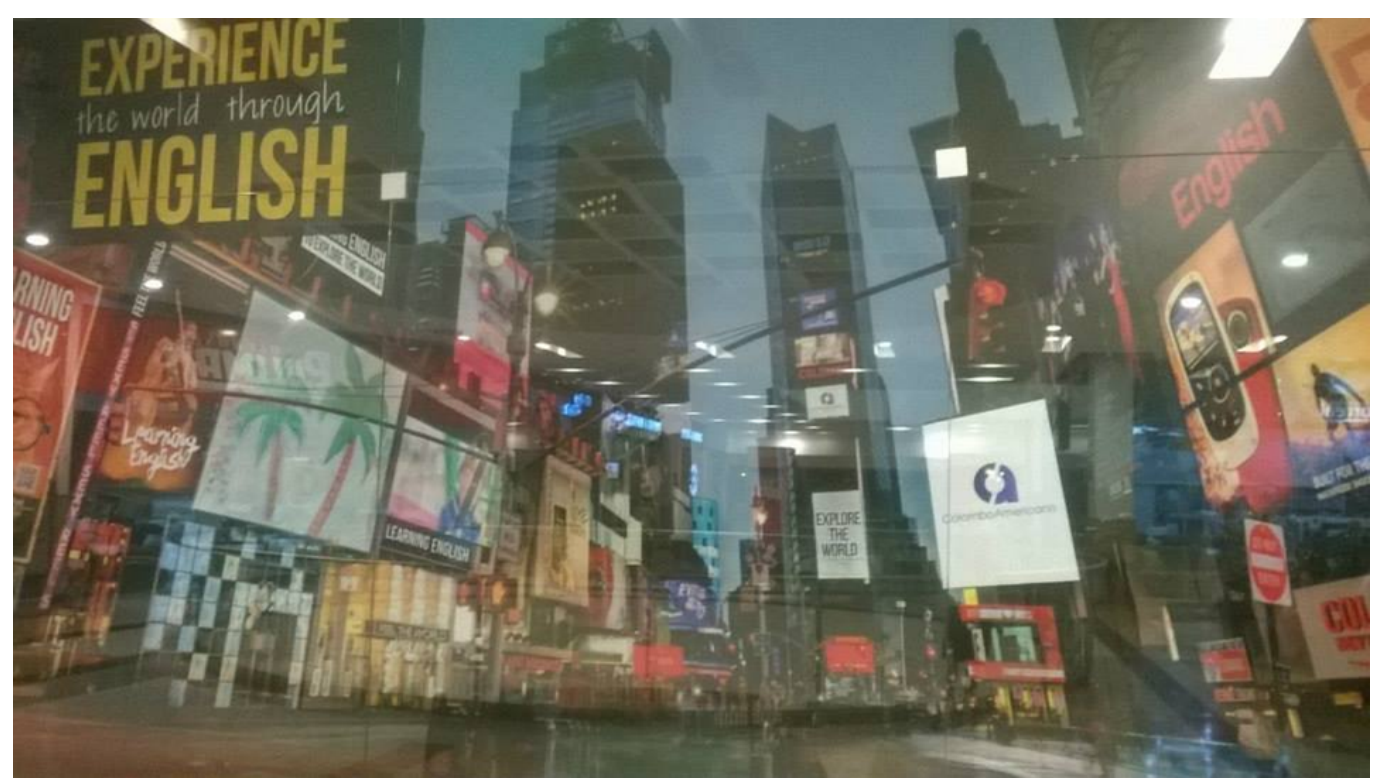

Figure 2

English Language Center Advertisement Used for Diagnosis

At this point, Jessica and Laura did not provide any answer when answering the question "What messages about socio-cultural, political, historical, or economic issues are portrayed by the text?" In an informal conversation, they expressed that they did not see any issues in that text and, therefore, were not able to answer the question (personal communication, September 1, 2015). Nevertheless, by the end of the analysis stage (week 11), in their analysis of food or drink advertisements, these two participants were able to unveil messages about community issues portrayed by commercial media.

That week, they analyzed one advertisement of a national beer brand named Pilsen, which included a couple of sentences in which a colloquial language register was used: "Mostro, estoy que me [picture of a Pilsen beer]" ["Monster, I am about to Pilsen" or "Dude, I am craving a Pilsen"] and "Entre nosotros nos entendemos" [We know what we mean]. The ad also included a hashtag for social media referencing: \#NoEsPaisaSi [\#NotPaisaUnless] and presented some information about the prohibition of selling alcoholic beverages to underage people and a warning about the possible health damages that excessive consumption of alcohol could cause, as Figure 3 shows. 
When answering the question "What messages about socio-cultural, political, historical, or economical issues are portrayed by the text?" they wrote:

The text is related to alcoholism and the damages it brings to consumers. These issues are reflected in health, the economy and interpersonal relationships. "Harmful use of alcohol is one of the twenty leading causes of lost years of life, it is estimated to account for $5.1 \%$ of the global burden of disease and disability adjusted injuries. Also, it causes deaths and disability in a range of relatively early ages. For the consumer population between 20 and 39 years, 25\% of the deaths caused by alcohol" (Delaurbe, 2014). (...) The messages that are being conveyed by this text are related to social exclusion. Such as: To be Paisa, you must drink Pilsen. To understand this advertisement, you must be paisa. ${ }^{1}$

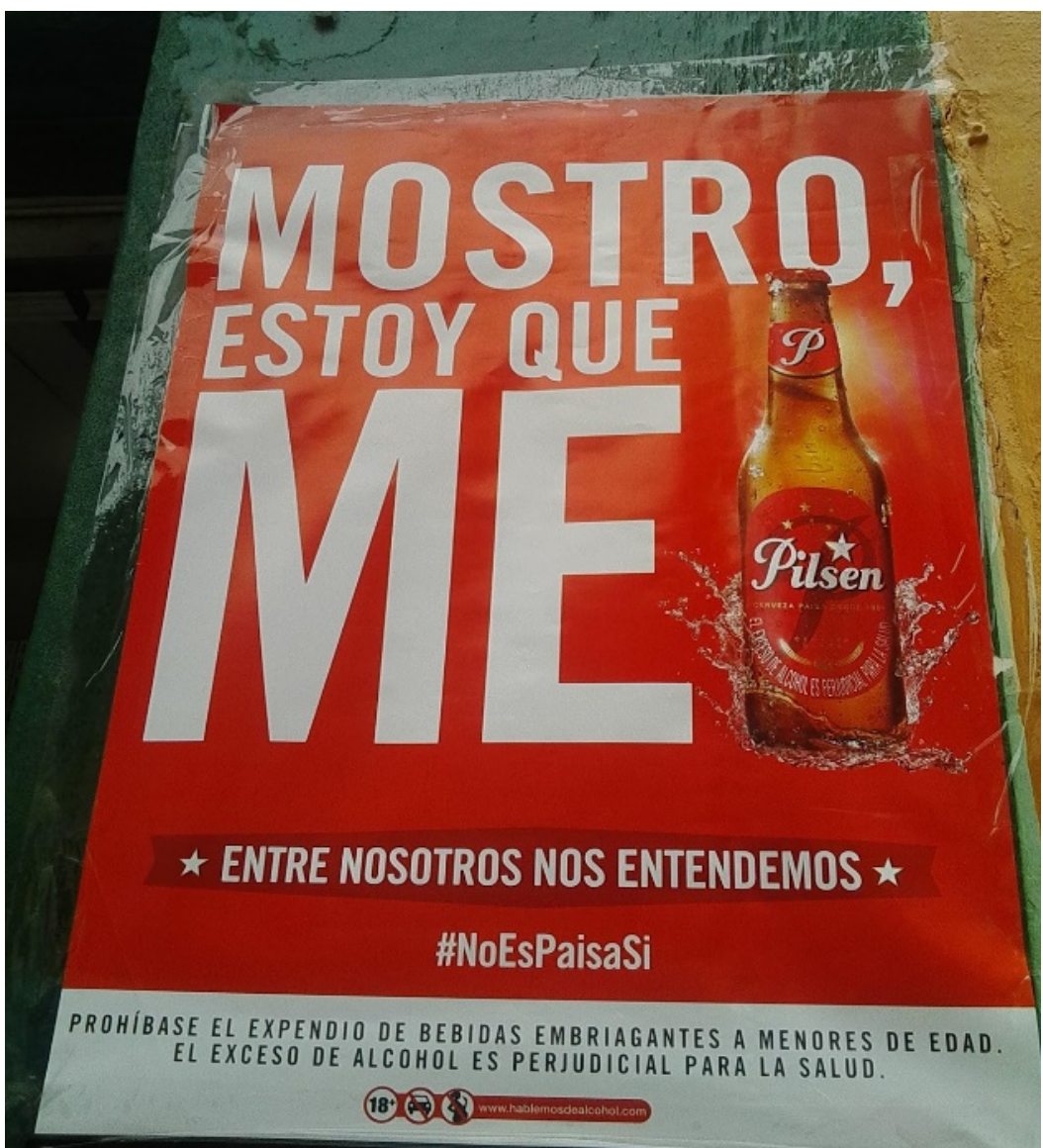

Figure 3

Beer Advertisement Analyzed by Jessica and Laura

In this analysis, although with a different advertisement, not only were Jessica and Laura able to provide an analysis of the messages about social issues conveyed by

1 All participants' comments were reproduced unfiltered and unedited. 
media texts (e.g., alcoholism, death, disability), but also did they start to uncover and problematize some hidden messages about social exclusion (i.e. to be paisa, you must drink Pilsen; to understand this advertisement, you must be paisa).

Their analysis suggests that the dialogues about social issues, the examination of the materials about advertisement and society, the critical questions, the analysis practice tasks, the peer and teacher feedback, and the sharing activities completed during this course helped them develop critical awareness of the messages in advertisements. These tasks seem to have provided them with more elements to understand how media convey hidden messages, which can promote, validate or disseminate sociocultural issues affecting our health (as in the case of alcoholic drinks) and our human interactions (as in the social exclusion they could unveil in that advertisement).

\section{Awareness of the Non-Neutral Nature of Media}

All participants developed awareness of the non-neutral nature of media texts. That is, they showed understanding that these texts reflect multiple purposes, target some audiences and exclude others, and represent some groups of people and exclude others. The following paragraphs provide evidence by presenting two examples that represent participant's gains in deconstructing the non-neutral nature of media.

The first example is the case of Abril and Sebastián, which exemplifies how participants expanded their awareness of the multiple purposes of media texts. They analyzed real estate advertisements for their class project. In their first analyses (diagnosis and practice), these participants were able to uncover the economical purpose behind advertisements. They analyzed an advertisement of an apartment project called Alejandría. This advertisement portrayed a nuclear white family (father, mother, son and daughter) having a happy moment as parents play with their children by carrying them on their backs, as Figure 4 shows.

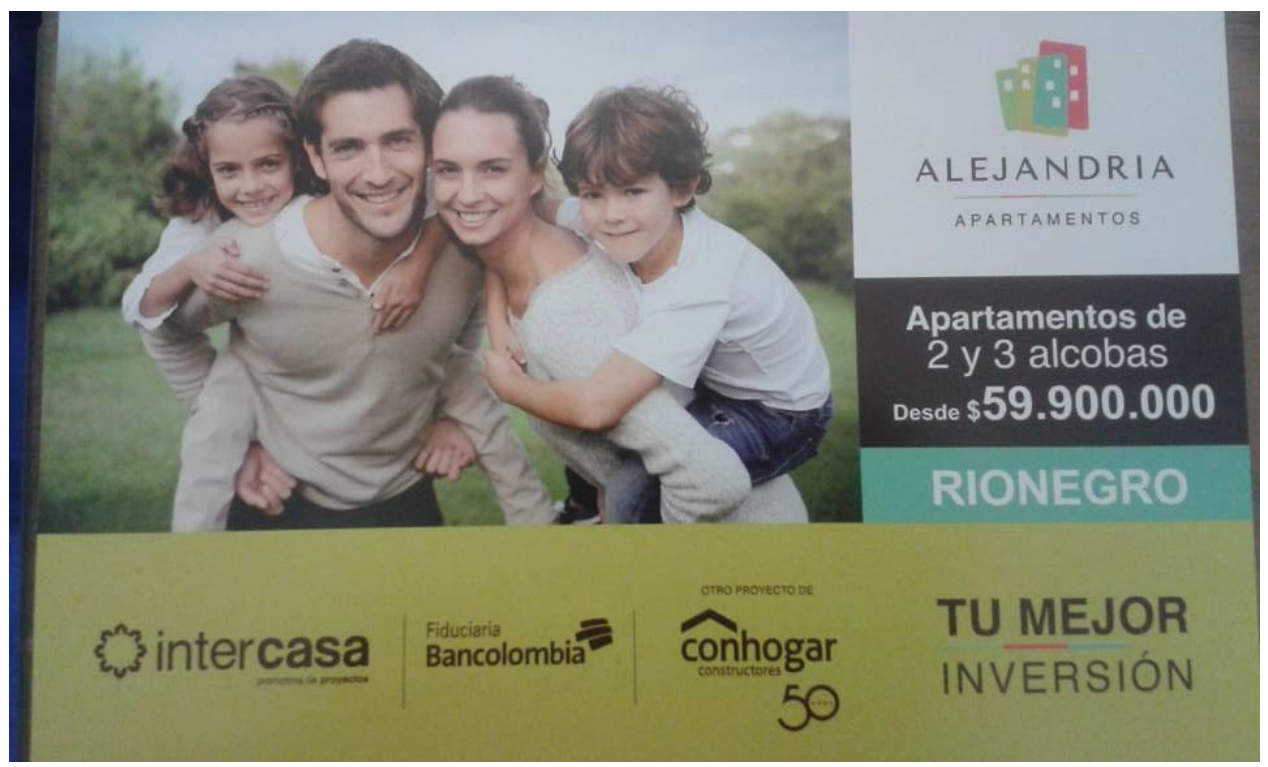

Figure 4

Alejandría's Advertisement Analyzed by Abril and Sebastián 
When Abril and Sebastián individually answered the question "What is the purpose of this text?" they wrote "As an advertisement, this text has a commercial purpose, to sell apartments" (Critical Analysis Diagnosis, Sebastián, 10/13/15), and "The purpose of this [text] is motivates the people to buy a house" (Critical Analysis Diagnosis, Abril, 10/13/15). These two answers demonstrated clarity about the most salient purpose of real estate advertisements: to sell an apartment or a house.

However, later in their analysis, Abril and Sebastián could unveil other purposes of real-estate advertisements. For instance, when answering the question "What impact do you think these texts in the public space have on people in general?" in the Reflection Task \#4 conducted in the tenth week, they stated "la publicidad no vende solo un producto si no también valores que afectan a la sociedad" [advertising not only sells a product, it also sells values that affect society]. In the same task, when answering the question "What impact do they have on the people from your community?" they wrote "The [public space] full of ads sell the ideas of success [emphasis added] and lifestyle that people need to have if they want to be happy." As can be observed, Abril and Sebastián's latter assertions show evidence of a more thorough deconstruction of the purposes behind real-estate advertisements. This time, besides identifying the most salient purpose of advertisements (to sell a product), these participants acknowledged that these texts also seek to sell values, lifestyles, ideals about success, and even happiness.

The second example is the case of Vanessa, which illustrates participants' awareness of how media target and exclude audiences. At first, in a practice task conducted in the ninth week, she barely acknowledged that advertisements target certain audiences. In that exercise, Vanessa analyzed a political advertisement of an educational project called Antioquia, la Más Educada [Antioquia, the most educated] located on a main road near to the entrance of her town. Through this project, Antioquia's government invested resources in the construction of big educational parks in different towns in the whole department. The political advertisement analyzed by Vanessa included, from left to right, the motto of the project "Cuando no se pierde un peso se puede" [When not a single peso is wasted, it is possible], a big green checkmark, a picture of one of the educational parks, and the logo of the whole project, shown in Figure 5. When answering the questions "Who does the text target? Who is not targeted?" Vanessa's first response was "Everybody is target of this text" (Critical Analysis Practice, Vanessa, 10/27/15). At this point, since the text was located in a road with much circulation, Vanessa seemed to have inferred that everyone was its potential audience. 


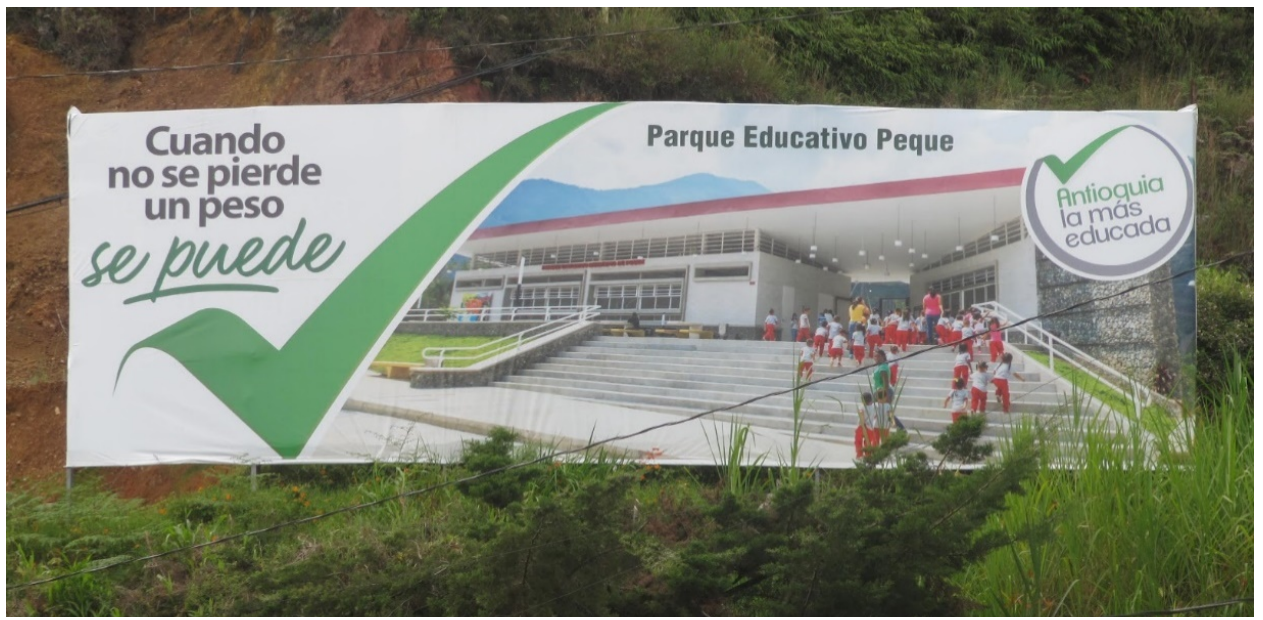

Figure 5

Advertisement of Educational Park Analyzed by Vanessa

Nevertheless, by the eleventh week, after completing the tasks proposed in the analysis stage (e.g., exploration of the material from the online course on advertisement and society, analysis practice tasks, peer and teacher feedback, sharing activities), she could significantly expand her awareness of this text's audience. Indeed, in a posterior analysis of the same advertisement, Vanessa wrote:

This text includes an ample audience, going from young people (...) to old people that had to make a choice on the last elections. It includes women, farmers, worker people, students, professionals, and truck drivers. People with a high purchasing power are also targeted, because they are who have to pay higher taxes. Being in their place, I would like to see that my money is "properly" spent. Imprisoned persons, hospitalized patients, or hospitalized in [elder homes] are not addressed. (Critical Analysis of Text 1 Draft 2, Vanessa, 11/10/15)

Vanessa's analysis was much more elaborate in her second draft. In this analysis, she was aware of different target audiences of this text (e.g., voters, farmers, tax payers) and of people who were not being targeted (e.g., people in prisons, hospitals, or elder homes). For this participant, the exclusion of audiences seems to be related to the fact that some people could not actually pass by this advertisement. Besides, she provided a possible reason for which this text had such a wide audience: it wanted to show people that public money was being invested properly.

These two examples suggest that the dialogues about social issues, the examination of the materials about advertisement and society, the critical questions, the analysis practice exercises, the peer and teacher feedback, and the sharing activities completed during this course were useful in helping participants gain awareness and deconstruct the non-neutral nature of media texts.

\section{From Awareness to Informed Choice Making}

Data showed that even though during the course of the English composition class there was not an opportunity to materialize any type of individual or collective 
transformative actions involving media, public space and social issues, all participants were able to make informed choices. Six participants later decided not to engage in social transformative actions. The other two participants were inspired and decided to take a step further to engage in social justice.

Firstly, six of the eight participants (Abril, Jessica, Kelly, Laura, and Manuel) expressed to have transformed at an individual level after their participation in this study. Nevertheless, they chose not engage in transformative actions at a community level as they felt that engaging in activist actions was challenging for them. Laura is an example of this. She wrote:

I have not been directly involved in some kind of action. After my participation in this project, I am more aware of the influence of [publicly displayed] texts in society and all the problems that they bring. But I have realized that trying to generate a change is a very difficult task; since we like to be in a comfort zone, we are facile people; we prefer to live on appearances, believe that everything is fine and we are used to run away from problems. Perhaps, we are afraid to face reality and react when it is too late (Questionnaire \#5, Laura, 03/31/15)

Even though, she admitted she had gained awareness about the issues associated with media, she chose not to take any transformative actions at a larger scale. For her, it would be a hard task, which would take her out of her comfort zone.

Secondly, the participation in this study inspired two of the participants to engage in community transformative actions. One example is Sebastián, who in the final questionnaire expressed:

Solamente he participado de una marcha por la defensa del territorio. Esto como protesta ante el fenómeno de desplazamiento por la valorización de la tierra y los macro-proyectos de infraestructura en el oriente antioqueño. Solamente eso por el momento [I have only participated in a march for the defense of territory. This was a protest against the displacement phenomenon caused by the [increasing price of land] and the infrastructure macro-projects developed in [our region], just this for the moment] (Questionnaire \#5, Sebastián, 03/31/15)

Sebastian's engagement in a march aiming at defending his community's territory demonstrates his emerging commitment with transforming at least one of the issues he saw in the real estate advertisements located in his community's public space. Yet, his statement, "I have only participated in a march (...) just this for now," suggests that he feels that this is not enough and that he could do more. It could even suggest that he wishes to continue to participate in other transformative actions.

Similarly, Carlos showed disposition to contribute to social justice. In his final questionnaire, he wrote: 
Mi participación se ha limitado sólo a charlas y debates acerca [de los textos en el espacio público] con familiares y amigos aportando mis perspectivas, que obviamente están influidas por todo lo que hice durante el proyecto (...) no me siento en capacidad de intervenir a más escala aunque si he pensado en un futuro intervenir de algún modo. [My participation has been limited to conversations and debates about [texts displayed in public spaces] with family and friends in which I have contributed with my perspectives, which are obviously influenced by all I did in the project (...) I do not feel able to intervene at a larger scale, although I have indeed thought about intervening in the future, somehow] (Questionnaire \#5, Carlos, 03/31/15)

Although Carlos does not provide details about the talks, discussions, and his perspectives, his commitment with sharing and having conversations about media displayed in public spaces with friends and relatives shows his way of acting towards what he learned in the course. Besides, he expresses intentions to continue to take transformative actions as he states that he would like to develop intervention in the future.

\section{DISCUSSION AND CONCLUSIONS}

As the evidence presented here shows, all pre-service teachers developed their critical awareness of media texts displayed in public spaces, particularly advertisements. As such, they expanded both their awareness of the hidden messages about community issues portrayed by these texts and their understanding of the non-neutral nature of these texts. Besides, all participants made informed choices about their participation in transformative actions addressing issues of advertisements in the public space.

This study suggests that various factors facilitated such achievements. To begin with, the critical questions that participants received facilitated the deconstruction of both the non-neutral nature of advertisements and the messages about socio-cultural issues they convey. These questions might have fostered their awareness development even from the very first moment in the diagnosis tasks. Therefore, as Freire and Faundez (2013) suggest, teaching and learning begin with a question, as questions trigger curiosity and discovery.

Nevertheless, although the questions that I provided were helpful, in the future, I would try to either improve them or incorporate more to better assist students in deconstructing hidden messages conveyed by media texts and their nonneutral nature. For example, besides asking What messages about socio-cultural, political, economical, or historical issues are portrayed by this text? I would provide complementary questions such as:

- Who is talking to whom in this text?

- What do the author(s) want to say?

- What hidden messages could the text convey? What does the text say about community issues? 
In addition, I would incorporate questions that allow students to dig deeper in the analysis of how people are represented and how those representations can be related to power issues and social injustice. That is, besides asking questions such as Which groups of people are being represented in this text? Which are not? What could be some possible reasons and consequences? I would ask:

- How are those people being represented or misrepresented?

- How could those representations affect people in your community?

- What does the text say about power relations and injustices? (Luke, 2000; McLaughlin \& DeVoogd, 2004; Morrel, 2014).

Last, I would try to better help participants to further evaluate the reasons behind the targeted audiences of media texts, to think about how media producers use strategies to address certain audiences, and even to uncover unequal relations among people. In addition to asking Who does the text target? Who is not targeted? Why? I would also ask:

- How does this text target some audiences and exclude others?

- Why could those audiences be addressed?

- Why are certain groups of people excluded?

- How would this impact human interrelations in your community?

Besides the critical questions employed, other factors may have contributed to participants' development of critical awareness of media. First, the In-Vivo Encounters were key to trigger awareness from the beginning of the study. These encounters allowed participants to examine advertisements displayed in public spaces of their own rural communities. This might have given them the opportunity to make realizations about the role of commercial media in their everyday lives.

Second, building knowledge about the genre of advertising seems to have had an important impact in the development of these pre-service teachers' critical awareness of media. The material from the online course on advertising offered by University of Duke, North Carolina helped pre-service teachers examine the relation of advertisement to society, culture, history and economy. Besides, exploring such material might have helped them understand, among other aspects, how advertisements sell values, ideas of success, and lifestyles.

Next, all the opportunities for dialogue and for peer and teacher feedback also aided the deconstruction of the non-neutral nature of media texts and of the messages about socio-cultural issues they convey. Having such opportunities for dialogue and feedback seems to have helped this group of pre-service teachers observe with a more skeptical eye the manipulation and impact that media producers expected to have on them (Jolls, 2012; Luke, 2012). They could have also helped them to become active meaning makers of media texts (Kellner \& Share, 2005), to be more sensitive about social problematics, and to make informed interpretations about the hidden messages conveyed by these texts (Gainer, 2010; Kellner \& Share, 2005). 
Last, the analysis and reflection about social transformative actions taken by people locally and in other parts of the globe helped pre-service teachers to envision possible actions that could be taken in their own communities and, then, to make informed choices of action. As Freire and Macedo (1997) state, to participate in social transformation, self-formation is required. Indeed, "to every understanding, sooner or later an action corresponds" (Freire, 1974, 39). In this regard, Jolls (2012) asserts that by being able to deconstruct texts, people can "control the meaning that they make from the message and how they might want to respond in making decisions or taking action" (29).

This study also suggests that critical awareness of media may not always be followed by activist actions. Actions can stay at an individual level (Jolls, 2012). In our country, especially in rural areas, students are not accustomed to speaking out or engaging in the transformation of social issues or injustices. The lack of critical education from elementary school and our history of conflict and violence often may prevent people from raising their voices and taking activist actions. For instance, today, dozens of social leaders are being silenced and murdered in Colombia, even after the National Peace Accord signed in November, 2016 (Colombia Informa, 2019). Therefore, it is just expected for people to feel vulnerable and to choose not to participate in social justice actions. Of course, this is not the case of all ELT educators in rural or urban areas, but it is certainly part of the whole picture.

Becoming critically aware of media will not happen overnight for English pre-service or in-service teachers in Colombia. As such, this task cannot be addressed only by teachers' isolated efforts or in one course. It should be a sustained exercise along teacher education programs, as suggested by Gainer (2010). Hence, this study suggests implications for teachers, teacher educators and teacher education programs. To begin with, teachers and teacher educators face the challenge and the responsibility of educating new generations of teachers who are not only more sensitive and critical about global issues, but also more willing to actively participate in their transformation. Regardless the obstacles that we may face, we should not give up. For instance, even though sometimes I have felt at loss or isolation when developing critical awareness of media in my capacity as English teacher and teacher educator, I continued to study available literature, to participate in research projects and conferences, and tried to collaborate with other colleagues by sharing and reflecting on our practices. Therefore, teacher educators who wish to nurture critical awareness of media in their instruction must engage in continuous professional development, practice, collaboration and critical reflection.

In like manner, this study states the need for ELT teacher education programs to incorporate critical approaches to language education in the curriculum and to facilitate teacher educators' access to professional development opportunities. In fact, teacher educators may need the opportunity to develop critical awareness of media themselves and to examine multiple ways to help students develop such critical awareness. To achieve this, a collaborative collegial work at a larger scale is paramount. For instance, teacher education programs should work along with experienced researchers and educators to share knowledge and experiences through workshops or presentations. This is one way in which 
teachers of teachers could engage in deconstructing media texts critically. Besides, English teacher education programs should facilitate the conditions for teachers to join efforts in designing courses, units and lessons, and even to conduct research aiming at developing students' critical awareness of media.

Lastly, this study opens opportunities for further research in at least two different aspects. First, this study examined how pre-service EFL teachers developed critical awareness of media during one course. However, it did not explore the implications that a project like this could have on pre-service teachers' philosophy of education, language acquisition process, or their literacy development. Longitudinal studies could be conducted to analyze how an intervention like this helps them with the development of these aspects as well. Second, this study was conducted with a small number of pre-service EFL teachers who lived in rather rural small towns and during a short period of time. Further research could explore how other pre-service EFL teachers in urban areas build critical awareness of media displayed in public physical and virtual spaces. Future studies could also give account of students' development of critical awareness of media across longer periods of time.

\section{REFERENCES}

Adichie, C. (2009, July). Chimamanda Ngozi Adiche: The danger of a single story [Video file]. Retrieved from http://www.ted.com/talks/chimamanda_adichie_the_danger_of_a_single_s tory

Alma Mater UdeA. (2014, September 29). U de A - Medellín, ciudad joven. Víctor artista visual. Comuna 3 [Video file]. Retrieved from https://www.youtube.com/watch?v=U UD I2Apeg

Alzate, M. (2016). Tenth graders' critical reflection on reggaeton video clips: A critical media literacy approach (Unpublished bachelor's thesis). Universidad de Antioquia, Medellín, Colombia.

Arias, N. (2017). Using a critical media literacy approach to analyze media texts in an english class for children (Unpublished master's thesis). Universidad de Antioquia, Medellín, Colombia.

Aristizábal, A. (2016). Fostering 10th graders critical reading of fashion advertisements (Unpublished bachelor's thesis). Universidad de Antioquia, Medellín, Colombia.

Begoray, D. Wharf Higgins, J. Harrison, J. \& Collins-Emery, A. (2013). Adolescent reading/viewing of advertisements: Understandings from transactional and positioning theory. Journal of Adolescent \& Adult Literacy, (57)2, 121-130.

Camargo, J. (2017). Developing critical media literacy in an eleventh grade EFL class in Medellín, Colombia (Unpublished master's thesis). Universidad de Antioquia, Medellín, Colombia.

Colombia Informa. (2019, January 8). Continúa persecución de líderes sociales en Colombia. Retrieved from http://www.colombiainforma.info/continuapersecucion-de-lideres-sociales-en-colombia/ 
Freire, P. (1974). Education for critical consciousness. New York: Continiuum.

Freire, P. \& Macedo, D. (1997). Literacy: Reading the world and the world. Wesport, CT: Bergin \& Garvey.

Freire, P. \& Faundez, A. (2013). Por una pedagogía de la pregunta: Críticas a una educación basada en respuestas a preguntas inexistentes. Buenos Aires: Siglo Veintiuno Editores

Gainer, J. (2010). Critical media literacy in middle school: Exploring the politics of representation. Journal of Adolescent \& Adult Literacy, 53(5), 364-373.

Guapacha, M. (2015). Critical media literacy: Helping secondary ELLs read representations of women in newspapers (Unpublished bachelor's thesis). Universidad de Antioquia, Medellín, Colombia.

Guerra, E. (2015). Critical media literacy: Reading critically body images in advertisements with EFL tenth graders in Colombia (Unpublished bachelor's thesis). Universidad de Antioquia, Medellín, Colombia.

Guion, L, Diehl, D, \& McDonald, D. (2011). Triangulation: establishing the validity of qualitative studies. University of Florida: IFAS Extension.

Huberman, M. \& Miles, M. (1994). Data management and analysis methods. In N. Denzin \& Lincoln (Eds.), Handbook of qualitative research (pp. 428444). Thousand Oaks, CA: Sage.

Jolls, T. (2008). Literacy for the $21^{\text {st }}$ century: An overview \& orientation guide to media literacy education. Malibu, CA: Center for Media Literacy.

Jolls, T. (2012) Media literacy: A system for learning anytime, anywhere. Malibu, CA: Center for Media Literacy.

JR. (2011, March). JR: My wish: Use art to turn the world inside out [Video file]. Retrieved from http://www.ted.com/talks/jr_s ted prize wish use art to turn the world inside out

Kellner, D., \& Share, J. (2005). Toward critical media literacy: Core concepts, debates, organizations, and policy. Discourse: Studies in the Cultural Politics of Education, 26(3), 369-386.

Kellner, D., \& Share, J. (2007). Critical media literacy is not an option. Learning Inquiry, 1(1), 59-69.

Luke, A. (2000). Critical literacy in Australia: A matter of context and standpoint. Journal of Adolescent \& Adult Literacy, 43(5), 448-461.

Luke, A. (2012). Critical literacy: Foundational notes. Theory into Practice, 51(1), 4-11.

Luke, A. \& Woods, A. (2009). Critical literacy in schools: A premier. Voices from the Middle, 17(2), 9-18.

McLaughlin, M. \& DeVoodg, G. (2004). Critical literacy as comprehension: Expanding reader response. Journal of Adolescent \& Adult Literacy, 48(1), 52-62.

Miles, M., Huberman, M. \& Saldaña, J. (1994). Qualitative data analysis: A methods sourcebook. Thousand Oaks, CA: Sage.

Mora, R. \& Muñoz, R. (2012, November). A critical deconstruction of TV ads for online English courses: Toward a reconstruction of the concept of second language. Paper presented at ICERI 2012 Conference, Madrid, España. 
Morrell, E. (2002). Toward a critical pedagogy of popular culture: Literacy development among urban youth. Journal of Adolescent \& Adult Literacy, 46(1), 72-77.

Morrell, E. (2014). Popular Culture 2.0: Teaching critical media literacy in the language arts classroom. The New England Reading Association Journal, $50(1), 5-7$

Morrell, E. \& Duncan-Andrade, J. (2002) Promoting academic literacy with urban youth through engaging hip-hop culture. English Journal, (9)6, 88-92

Orrego, J. (2016). Critically deconstructing news articles with EFL fifth graders in Colombia (Unpublished bachelor's thesis). Universidad de Antioquia, Medellín, Colombia.

Perez, L. (2013). Unveiling Social Awareness through Literacy Practices in an EFL Class. Colombian Applied Linguistics Journal, (15)2, 184-204.

Richards, K. (2003). Qualitative inquiry in TESOL. NY: Palgrave Macmillan. Thoman, E., \& Jolls, T. (2003). Literacy for the 21st Century: An overview \& orientation guide to media literacy education. Los Angeles: Center for Media Literacy.

Vargas, M. (2010). Towards a discourse for criticism in language teaching: Analysis of sociocultural representations in mass media. PROFILE: Issues in in Teachers' Professional Development, 12(2), 179-190. 